\title{
Um estudo sobre o perfil qualitativo de candidatos à esterilização masculina na região sul do Brasil
}

\author{
Daiane Costa Trisch* \\ Sabrina Daiana Cúnico**
}

\begin{abstract}
Resumo
Trata-se de um estudo qualitativo que teve como objetivo analisar o perfil de candidatos à esterilização masculina e suas expectativas diante do procedimento realizado pelo Sistema Único de Saúde (SUS). Participaram do estudo cinco homens, candidatos à realização do procedimento. Os dados foram coletados por meio de entrevistas semiestruturadas e foram analisados seguindo os pressupostos da análise de conteúdo. Os resultados apontaram que, dentre as motivações dos participantes para a realização do procedimento está a satisfação com a quantidade de filhos que possuem, estando de acordo, em sua maioria, com o planejamento familiar realizado pelo casal. Problemas relacionados ao uso de métodos contraceptivos, principalmente com o uso de anticoncepcional oral pelas mulheres, também motivaram a decisão dos participantes em realizar o procedimento, considerando seus efeitos colaterais a longo prazo para a saúde da mulher. De acordo com as expectativas apresentadas pelos participantes, verificou-se que esperam, após a realização do procedimento, não se preocuparem com a concepção não planejada e, consequentemente, indesejada de filhos, além de ter uma melhor qualidade de vida e melhorias na vida em casal. Como consequências negativas, os homens abordaram o medo do procedimento falhar e a companheira voltar a engravidar, ou ainda a possibilidade de arrependimento, numa situação em que o homem deseje ter mais filhos com uma nova companheira.
\end{abstract}

Palavras-chave: Esterilização masculina; Planejamento familiar; Paternidade.

\section{A study about qualitative profile of candidates for male sterilization in southern Brazil}

\begin{abstract}
It is a qualitative study that aimed to analyze the profile of the candidates for male sterilization and their expectations regarding the procedure performed by the Brazilian Public Health System (SUS). The study included five men, candidates for the surgery. Data were collected through semi-structured interviews, analyzed according to the assumptions of content analysis. The results pointed that, among the motivations of the participants for the accomplishment of the procedure is the satisfaction with the number of children they have, being in agreement, for the most part, with the family planning carried out by the couple. Problems related to the use of contraceptive methods, especially with the use of oral contraceptives by women, also motivated the participants' decision to perform the procedure, considering their long-term side effects on women's health. According to the expectations presented by the participants, it was verified that they expect, after the procedure, not to worry about the unplanned and consequently unwanted conception of children, besides having a better quality of life and improvements in life in couple. As a negative consequence, the men approached the fear of the procedure failing and the woman returning to get pregnant, or the possibility of regret, in a situation in which the man wishes to have more children with a new partner.
\end{abstract}

Keywords: Male sterilization; Family planning; Fatherhood.

* Cesuca - Faculdade Inedi. Bacharel em Psicologia pela Faculdade Inedi - Complexo de Ensino Superior de Cachoeirinha

** Pontifícia Universidade Católica do Rio Grande do Sul. Psicóloga, Mestre em Psicologia (UFSM), Doutoranda em Psicologia pela Pontifícia Universidade Católica do Rio Grande do Sul (PUCRS) 


\section{Introdução}

São inúmeras as transformações vivenciadas pelas famílias nos últimos anos. Evidentemente, as variações nas dinâmicas e nas estruturas das famílias tiveram implicações também no desempenho dos papeis parentais (Cúnico \& Arpini, 2013). O homem que, até pouco tempo atrás, possuía características bastante claras no contexto familiar - atuando especialmente como provedor e impositor dos limites - passa a ter a sua participação requisitada também nos cuidados afetivos. Da mesma forma, a mulher, antes prioritária na educação e cuidado com os filhos, passa a não ter mais essa responsabilidade exclusiva, dividindo com os homens estes cuidados (Ramires, 2014).

Nesse contexto, o modelo de família organizado pelo princípio da hierarquia e orientado pela severidade de princípios, é substituído por maneiras distintas de organização, abrindo espaço para a vivência de arranjos familiares que contestam os modelos tradicionais e que impulsionam novas formas de relação (Cúnico \& Arpini, 2016). Em outros termos, se antigamente a ausência do pai no planejamento familiar e na rotina da família era, de certa forma, presumível, uma vez que a sua principal função era de prover materialmente os filhos e a esposa, hoje se percebe um movimento que se fortalece na atualidade, de pais mais participativos e afetivos.

Considerando o contexto de planejamento e ciclo vital familiar, é praticamente impossível descrever o homem sem referir aspectos relacionados à virilidade, $\mathrm{e}$ falar deste, na atualidade, sem mencionar a questão da paternidade. Isto porque, cada vez mais, existem novas formas de pensar a paternidade (Badinter, 1993). Gomes e Rezende (2004) ressaltam que, independentemente da importância da figura paterna, o homem, a caminho de se tornar pai, pode fragilizar-se perante a nova responsabilidade. $\mathrm{O}$ nascimento de um filho pode despertar no homem desejos inconscientes e fantasias associadas à morte e a situações que tenham ligação com a resolução de conflitos parentais.

Em estudo realizado por Jager e Bottoli (2011) sobre a paternidade, as autoras expõem as dificuldades em encontrar referências em psicologia que retratem os sentimentos do pai durante a gravidez do casal, sendo encontradas referências, quase que exclusivamente, sobre os sentimentos maternos. Situação que parece refletir o entendimento de que a figura paterna é coadjuvante durante a gestação e nascimento dos filhos, desconsiderando a importância da presença do pai desde a gestação, em especial no que se refere ao apoio à esposa/companheira.
As transformações acerca da paternidade ocorrem de forma lenta e gradual, podendo-se verificar a coexistência de várias formas de vivenciar a paternidade. Em alguns casos, o homem permanece com a responsabilidade de prover materialmente os filhos, ao mesmo tempo em que se preocupa com os seus cuidados e educação, antes exclusividade feminina, e com o vinculo e afeto em torno dessa relação (Oliveira \& Silva, 2011).

É importante ressaltar, todavia, que estas transformações não se constituem como uma realidade de todas as famílias. Pelo contrário, ainda é possível perceber práticas e dinâmicas bastante tradicionais, que refletem divisões de gênero estereotipadas e desiguais. Um exemplo destas práticas permeadas por estereótipos de gênero se refere ao envolvimento desigual de homens e mulheres nas questões de planejamento familiar, sendo a mulher tida - quase que exclusivamente - como a responsável pela contracepção e adoção de métodos anticonceptivos.

O planejamento familiar, projeto de lei aprovado em 1996, determina que as instâncias gestoras do SUS, em todos os seus níveis, têm a obrigação de garantir à mulher, ao homem ou ao casal, em toda a sua rede de serviços, assistência para concepção e contracepção como segmento das demais ações que constituem a assistência integral à saúde. Um ponto primordial desta lei é a implantação das práticas da laqueadura de trompas e da vasectomia como alternativas de anticoncepção (Ministério da Saúde, 2002). De acordo com o Ministério da Saúde (2002), o planejamento familiar deve ser abordado dentro do contexto dos direitos reprodutivos, tendo como objetivo fundamental garantir às mulheres e aos homens um direito básico de cidadania, previsto na Constituição Brasileira: o direito de ter ou não filhos ou filhas.

Mais do que apenas proporcionar assistência na escolha e uso efetivo de métodos contraceptivos às pessoas que buscam os serviços de saúde, o planejamento familiar também se torna fundamental para a qualidade na vida sexual e reprodutiva dos casais. Isto porque, ele também engloba questões socioeconômicas, a subjetividade de cada pessoa, o comportamento, o nível de saúde, a qualidade da relação afetiva entre o casal, etc. Vale mencionar, no entanto, que embora se trate de um programa voltado para a saúde sexual e reprodutiva do casal, ainda é possível perceber que as ações em planejamento familiar estão vinculadas à saúde da mulher e controle do número de filhos, não abrangendo de modo geral a população masculina (Camiá, Marin \& Barbieri, 2001).

De fato, o planejamento familiar ainda permanece fortemente vinculado a métodos anticoncepcionais vol- 
tados à mulher, visto que os principais métodos oferecidos pelo SUS à população no serviço de planejamento familiar são a pílula anticoncepcional, o dispositivo intra-uterino (DIU) e o injetável trimestral. Uma pesquisa realizada em quatro capitais brasileiras (Belém, Salvador, Curitiba e Goiânia) demonstrou que a participação dos homens no planejamento familiar ainda não ocorre de maneira efetiva principalmente no que se refere à responsabilidade pela contracepção (Osis, Faúndes, Makuch, Mello, Sousa \& Araújo, 2006).

Moreira, Costa, Araújo e Queiroz (2008), destacam como importante e fundamental disponibilizar a atenção aos homens nestes serviços, visto que, como já mencionado, a participação masculina é considerada quase que inexistente neste cenário. Uma das razões para a pouca participação dos homens nesse contexto pode ser explicada pelo fato dos homens considerarem que não precisam ter tanto cuidado com a saúde, pois isso é preocupação feminina. Essa conduta gera prejuízos para o casal, pois é atribuída quase que exclusivamente à mulher a responsabilidade pela contracepção e adoção de métodos anticonceptivos. O casal acaba por não conhecer outros métodos mais profundamente, e nem sempre faz uso daquele que é o mais adequado ao seu caso.

É por esta razão que se pontua a importância em dar o espaço para que os homens se posicionem como co-autores do processo reprodutivo integralmente, possibilitando a eles também o esclarecimento de suas dúvidas e a desmistificação dos conceitos e preconceitos que possam surgir quanto à sua participação na anticoncepção. Ressalta-se também a importância de oferecer um ambiente favorável para a reflexão sobre os papeis reprodutivos do homem, e não apenas oferecer informação personalizada, embora não sejam poucos os homens que desconhecem outros métodos contraceptivos para além do preservativo (Marchi, Alvarenga, Osis \& Bahamondes, 2003).

A esterilização masculina, também conhecida por vasectomia, é a contracepção permanente para homens que não desejam mais ter filhos. O procedimento cirúrgico consiste em uma pequena incisão no escroto, onde é localizado cada um dos dois tubos por onde o esperma é transportado até o pênis (vaso deferente). Após, corta-se e bloqueia-se o vaso escrotal, cortando e amarando-o, ou aplicando calor ou eletricidade (cautério). Em síntese, a vasectomia faz com que o sêmen não contenha mais espermatozóides, através do fechamento de cada vaso deferente. O sêmen é ejaculado, porém não pode gerar uma gravidez (Organização Mundial da Saúde, 2007).
De acordo com a Organização Mundial da Saúde (2007), a cirurgia de vasectomia não é totalmente eficaz durante os três primeiros meses após a realização do procedimento, mesmo sendo considerada segura e permanente. A gravidez pode ocorrer no primeiro ano após o procedimento, caso o casal não utilize outros métodos contraceptivos eficazes de forma contínua e correta nos primeiros três meses, até que a vasectomia possa atingir sua plena eficácia. É importante ressaltar que o procedimento de vasectomia é um procedimento permanente, uma vez que - geralmente - não é possível interromper ou revertê-la. A cirurgia de reversão é difícil, de alto custo financeiro e não é disponibilizada na maioria das regiões (Organização Mundial da Saúde, 2007).

Considerando as questões apresentadas e diante da necessidade de problematizar o envolvimento dos homens nas questões de planejamento familiar, o presente estudo apresenta uma análise do perfil de candidatos à esterilização masculina e suas expectativas diante da realização do procedimento, bem como suas representações sobre família e paternidade, a partir de parâmetros qualitativos.

\section{Método}

Trata-se de um estudo de caráter qualitativo, realizado por meio da aplicação de um questionário sociodemográfico e uma entrevista semi-estruturada. De acordo com Minayo (2012), a pesquisa qualitativa se ocupa de um grau de realidade que não pode ou não deveria ser quantificado. Trabalha com os significados, os motivos, as aspirações, as crenças, os valores e as atitudes. Esse grupo de fenômenos humanos é compreendido como parte da realidade social, visto que o ser humano diferencia-se não somente pelo agir, mas pelo pensar sobre o que faz e pela interpretação de suas ações dentro e a partir da realidade vivida e dividida com seus semelhantes.

O presente estudo contou com a participação de cinco homens, na faixa etária entre 25 e 43 anos, residentes em uma cidade do sul do Brasil e que possuíam entre dois e cinco filhos vivos. De acordo com os parâmetros que guiam o SUS, os critérios para a realização da vasectomia são os seguintes: ter no mínimo 25 anos de idade; ter no mínimo dois filhos vivos; ter estabilidade conjugal (se estiver casado) e haver comum acordo do casal (Ministério da Saúde, 2009).

Em função desta clara demarcação de critérios estabelecidos pelo SUS, neste estudo, o perfil dos participantes entrevistados será analisado de modo qualitativo, uma vez que seria redundante apresentar seus perfis de maneira descritiva. Assim, para além de contextualizar as 
informações sociodemográficas destes homens, esperamos compreender suas expectativas e motivações para a realização deste procedimento, entendendo quem são esses sujeitos e quais são suas concepções diante de conceitos como família, paternidade e planejamento familiar.

Dentre os participantes da pesquisa, houve um que expôs não possuir estabilidade conjugal sendo, portanto, solteiro. Considerando os critérios já apresentados para a realização do procedimento no SUS pode-se pensar que este indivíduo não terá aprovação para a realização do procedimento de esterilização masculina, uma vez que não preenche um dos critérios de inclusão. No entanto, em função das entrevistas terem sido realizadas em período anterior à avaliação psicossocial, optou-se por não excluir esse participante da pesquisa.

Para realização deste estudo utilizou-se como instrumentos um questionário sociodemográfico, contendo informações relativas à idade, escolaridade, profissão, estado civil, número de filhos, sexo e idade dos filhos, e número de filhos com a atual esposa/companheira; além de uma entrevista semiestruturada, a qual foi dividida em 3 (três) eixos: Família, Procedimento (cirurgia) e Expectativas.

Segundo Gaskell (2002) a entrevista qualitativa visa mapear e compreender o mundo da vida dos respondentes, e permite ao entrevistador inserir esquemas interpretativos para compreender as narrativas dos atores em condições mais conceituais e abstratas, muitas vezes em relação a outras observações. A entrevista qualitativa fornece os dados fundamentais para o desenvolvimento e a compreensão das relações entre atores sociais e sua condição. Objetiva uma compreensão detalhada das crenças, atitudes, valores e motivações, referente aos comportamentos das pessoas em contextos sociais específicos. Sendo assim, a compreensão em maior profundidade proporcionada pela entrevista qualitativa, possibilita fornecer informação contextual relevante para ajudar a explicar achados específicos.

Os participantes do estudo foram selecionados a partir de contato com um hospital localizado em uma cidade do sul do Brasil, através de um Projeto de Pesquisa que passou pela aprovação do Comitê de Ética em Pesquisa (CEP) da referida instituição. Após, iniciou-se a coleta de dados dos participantes - candidatos ao procedimento de esterilização masculina - que estavam nas imediações da instituição para avaliação médica, psicológica e social. Durante a espera para atendimento entre as avaliações psicológica e social, os participantes foram abordados para a participação no estudo. As entrevistas foram gravadas em áudio e transcritas para que houvesse maior fidedignidade das informações. Salienta-se que, para aplicação dos instrumentos de pesquisa citados anteriormente, todos os participantes obtiveram uma breve explicação sobre o Termo de Consentimento Livre e Esclarecido (TCLE), o assinaram, e receberam uma das vias do mesmo.

A análise de conteúdo, obtida após a aplicação dos questionários sociodemográficos e realização das entrevistas semiestruturadas, seguiu a metodologia proposta por Bardin (2011), que se divide ao longo de três polos cronológicos: 1) a pré-análise - objetiva transformar as ideias iniciais em operacionais e sistematizá-las, para um plano de análise, utilizando-se da leitura "flutuante", estabelecendo contato com os documentos a analisar; 2) a exploração do material - operações de codificação, decomposição ou enumeração, em atribuição de regras previamente formuladas; 3) tratamento dos resultados obtidos e interpretação - determinar quadros de resultados, diagramas, figuras e modelos, que sintetizam e põem em relevo as informações fornecidas pela análise.

Salienta-se, por fim, que este estudo está amparado pela Resolução 466/2012 (2012) do Conselho Nacional de Saúde e a Resolução (RDC - 39/2008) da Diretoria Colegiada da Agência Nacional de Vigilância Sanitária.

\section{Resultados e discussão}

Os resultados serão apresentados a partir de duas categorias de análise, quais sejam: "Perfil qualitativo: família e paternidade" e "Vasectomia: motivacõos e expectativas".

\section{Perfil qualitativo: família e paternidade}

De modo geral, o planejamento familiar de casais envolve o nascimento de filhos em comum. Em estudo realizado sobre a vivência masculina na paternidade participativa, Sutter e Bucher-Maluschke (2008) determinam que a paternidade participativa é aquela que pressupõe o cuidado e o envolvimento permanente no cotidiano dos filhos, no âmbito da alimentação, higiene, lazer e educação. Vale mencionar que esses cuidados com os filhos podem variar bastante de homem para homem, de acordo com o grau de disponibilidade pessoal e de tempo.

$\mathrm{Na}$ atualidade, verificam-se diferentes conjunturas familiares e concepções de paternidade. Isso porque, os homens têm assumido papeis que até pouco tempo atrás eram considerados exclusivamente femininos, como exemplo, o cuidado dos filhos (Botton, Cúnico, Barcinski \& Strey, 2015) e, embora ainda de modo discreto, a participação ativa na contracepção do casal, muitas vezes assumindo para si a responsabilidade de não gerar mais 
filhos. Neste estudo, verificou-se que o entendimento de paternidade não cabe mais ao simples fato de conceber um filho e prover seu sustento, mas engloba várias questões relacionadas ao comportamento do pai e o bem-estar do filho, de acordo com a vinheta abaixo:

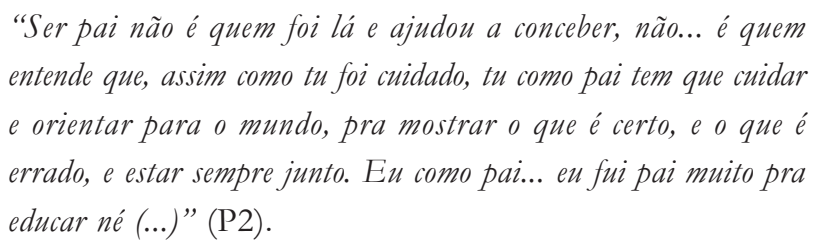
entende que, assim como tu foi cuidado, tu como pai tem que cuidar e orientar para o mundo, pra mostrar o que é certo, e o que é errado, e estar sempre junto. Eu como pai... eu fui pai muito pra educar né (...)" (P2).

Para Lima, Serôdio e Cruz (2011), a paternidade precisa ser vista de forma plural, ressaltando a sua base biológica, social, legal e simbólica. Concretiza-se em formas tangíveis de envolvimento, como a aceitação de responsabilidades paternas. Estas se relacionam ao envolvimento do pai na orientação ética e moral da criança, no sustento econômico da família, no apoio emocional, prático e psicossocial para companheira, ou na educação e cuidados dos filhos, conforme se pôde identificar na fala abaixo:

\begin{abstract}
"Ah, eu sou um bom pai, pra mim, eu me avaliando (...) Eu jogo bola com os meus filhos, eu estou sempre brincando com eles (...) Jogar vídeo game, eu não tenho aquele tempo às vezes (...) Mas sempre quando der eu estou sempre ali, brincando, ajudando, fazendo o tema também (...) Olho o caderninho da creche, a agenda do pequeninho que está na creche (...) O outro me explica como é que foi no colégio dele, que ele jogou bola, que ele aprendeu outros tipos de conta né (...)” (P3).
\end{abstract}

Lima, Serôdio e Cruz (2011) esclarecem ainda que o envolvimento paterno precisa ser estudado considerando sua amplitude, como recursos, condições e interações, compreendendo a interdependência dos diferentes sistemas sociais. Nessa perspectiva, o foco em formas de envolvimento concretizadas na interação com os filhos, ou na divisão de responsabilidades, apresenta-se associado a diversas transformações sócias históricas. Destas, pode-se considerar a profissionalização massiva do trabalho feminino, as modificações nas configurações familiares e as mudanças nas expectativas da sociedade em si diante do papel paterno.

Sobre a família, diferentemente do apresentado em alguns estudos (Azevedo, Gonçalves \& Rosa, 2013; Bezerra \& Rodrigues, 2010; Moreira, Costa, Araújo \& Queiroz, 2008; Vieira, Fábio, Gueleri, Picado, Yoshinaga \& Souza, 2005), nesta pesquisa percebeu-se um maior envolvimento do homem em questões como o planejamento familiar e o bem-estar da família de uma maneira geral, como segue em vinheta abaixo:

"Eu tenho uma relação estável de dez anos, nós tínhamos uma idéia um tempo atrás de termos um filho nosso, mas em função de questões financeiras né, o momento atual... ele não é favorável, pra médio prazo, tu pensar em colocar mais um filho no mundo né, aonde tu quer proporcionar o melhor, tu quer proporcionar uma boa escola, que infelizmente não temos né, um plano de saúde, enfim, essas questões básicas, que hoje nós não temos condições, pelo momento atual né, por também eu já ter três filhos, a minha esposa ter um filho (...)" (P2).

Em Vieira et al. (2005), verificou-se que a escolha pela vasectomia estava associada à maior idade e ao casamento, sendo realizada em menor número por casais que somente coabitava. Sobre a associação entre casamento e vasectomia, esta indica uma situação de maior compromisso entre os parceiros. Ou seja, a vasectomia estava associada à maior idade e ao casamento, com menor número de casais que coabitava, visto que, os homens que procuram o procedimento, em sua maioria, são casados, e a minoria não possui um relacionamento estável, o que indica um maior compromisso entre os parceiros na tomada de decisão pela vasectomia.

Embora na atualidade, ainda existam concepções tradicionais de família, em que o homem permanece como provedor financeiro, distante das decisões e responsabilidade no planejamento familiar, os participantes do presente estudo, demonstraram estar enquadrados em um novo modelo de pensar e agir a família e a parentalidade, pois, tratam-se, de homens que participaram ativamente do planejamento familiar com suas companheiras/esposas, assumindo para si essa responsabilidade. No que tange a parentalidade, demonstraram participação no cuidado e educação dos filhos.

\section{Vasectomia: motivações e expectativas}

Dentre as motivações que os participantes apresentaram para realização do procedimento de esterilização masculina, verificou-se que o fato de já terem tido a quantidade de filhos planejados tornou-se relevante, situação já sinalizada pelo estudo de Bezerra e Rodrigues (2010) e corroborada pela vinheta a seguir:

"Eu desejava ter filho. Sempre desejei, mas a princípio eu planejei dois (...) Não interessa o sexo, se é dois guri, duas guria, um casal (...) Veio dois guri, tá bom (...) É, dois filhos só” (P3). 
Além disso, verificou-se que problemas relacionados ao uso de métodos contraceptivos de barreira, como o preservativo masculino e o anticoncepcional oral, também motivaram os participantes a buscarem pelo procedimento de esterilização masculina, considerando que desejam sentir-se seguros de não conceber mais filhos, de acordo com a vinheta abaixo:

"É, eu fui pesquisar né, porque eu decidi não ter mais filhos, eu fiquei meio traumatizado com o segundo, então eu pesquisei, me informei que é um método, que é, como eu posso dizer, ele é... me esqueci a palavra, ele é seguro né (...) Ele não, não falha (...) Foi a situação do segundo filho, que a mãe dele tomava remédio, e eu usei a camisinha, a camisinha estourou, e não sei se ela esquecen o remédio em dia, o médico disse que acontece de uma em um milhão, de uma mulher que toma remédio a muito tempo engravidar (...) Eu estava me protegendo (...) E aconteceu de estourar a camisinha, e ai por isso que eu optei pela vasectomia" (P1).

Segundo Vieira et al. (2005), em estudo sobre as características dos candidatos à esterilização e os fatores associados ao tipo de procedimento, laqueadura tubária ou vasectomia, verificou-se que, dos 95 casais que se candidataram para cirurgia esterilizadora, $34(35,8 \%)$ se submeteram a vasectomia. Ainda de acordo com o estudo, a prevalência dos candidatos para esterilização, são casais estáveis, de baixa renda e escolaridade, que apontaram como motivos principais para esterilização a satisfação como o número de filhos e problemas relacionados à saúde; dos candidatos, um terço teve recomendação médica para não ter mais filhos. Através do uso de métodos anticoncepcionais reversíveis, grande parte dos candidatos já havia tentado limitar o número de filhos.

Neste estudo, ressalta-se também, como motivação para realização do procedimento de esterilização masculina, a preocupação com a saúde da mulher. Isto porque, as mulheres frequentemente utilizam, por um longo período de tempo, métodos contraceptivos como anticoncepcional oral e injetável, que provocam efeitos colaterais. As vinhetas abaixo são ilustrativas nesse sentido:

"Na verdade o grande objetivo é que realmente ela pare de tomar medicação também, eu não quero mais que ela tome anticoncepcional (...) Há muitos casos de câncer na família, na família dela principalmente, eu não quero mais hormônio, mais hormônio, e camisinha, eu não tenho mais idade pra usar camisinha né, não tenho mais (...) Pra que ela realmente não tome mais medicação, que pra mim não tem porquê, eu não tenho relacionamentos extraconjugais, só com ela, eu não quero que ela... eu não quero que ela tome mais medicamento, eu acho que é muito, sei lá, é muito arriscado, é muito arriscado" (P4).

"A minha esposa toma injeção, e ela está engordando, está com esse processo ai, ela quer parar de tomar a injeção (...) E ela está acima do peso também (...) É, mais é isso ai, saúde também dela, vai até melhorar se ela não tomar injeção" (P3).

Em concordância com este resultado, o estudo de Cícero, Mandadori, Marcon e Barreto (2014), observou que o fato de as mulheres não conseguirem adaptar-se aos anticoncepcionais orais, foi um dos motivadores para os homens decidirem por realizar o procedimento de esterilização. Sendo que, nestes casos, o aconselhamento referente ao planejamento familiar realizado pelos profissionais de saúde propôs outras formas de contracepção para os casais, como a vasectomia, favorecendo assim, a inserção do homem no serviço de saúde.

De acordo com as expectativas apresentadas pelos participantes, verificou-se que esperam, após a realização do procedimento, não se preocuparem com a concepção não planejada e, consequentemente, indesejada de filhos, além de ter uma melhor qualidade de vida e melhorias na vida em casal, como segue vinhetas abaixo:

"Vai ficar mais tranquilo pra mim, por causa dessa questão do medo de ocorrer um novo acidente, não que eu vá deixar de me prevenir né (...) De doenças né, então, mas na minha cabeça vai ficar mais tranquila essa situação do medo, que meio que me criou um bloqueio, pelo medo de ter outro filho" (P1).

"Bom, eu não vou mais me preocupar né, em ter filho (...) E ela vai poder largar, vai poder deixar de tomar a injeção também (...)” (P3).

"O que vai mudar de fato é ela deixar de tomar remédio né, porque se é algo que já está definido né, o que vai mudar de fato, é a questão dela não precisar mais tomar remédio né (...) E talvez. ter uma, uma condição melhor né, fisicamente" (P2).

Segundo Marchi, Alvarenga, Osis, Godoy, Guimarães e Bahamondes (2011), os homens que decidem pela vasectomia têm tendência a reconhecer o método como motivo de mudanças positivas, especialmente sobre a vida sexual e o relacionamento com a companheira e a família em geral. Percebeu-se uma melhor qualidade nas relações sexuais, o que indica a permanência da virilidade nos homens, contrariando a crença, ainda presente, de que a cirurgia de vasectomia pode levar a impotência sexual.

Os homens também destacaram como consequências da vasectomia, a melhora nas relações familiares 
como resultado da tranquilidade de poder relacionar-se sexualmente com suas parceiras sem medo de uma gravidez não planejada e indesejada, o que prejudicaria sua capacidade como provedor da família (Marchi et al, 2011). No entanto, embora decididos e - aparentemente - confiantes na realização do procedimento, os participantes demonstraram certo receio com a vasectomia, conforme demonstra a vinheta a seguir:

"Se en olhar para o cirurgião e ver ele tremendo, e ver ele estranho, ele não vai me operar, isso eu te garanto, mas quanto ao procedimento não... eu tenho mais medo do cirurgião né, tá de mau humor, alguma coisa nesse sentido, machucar o cara né, até porque se estragar alguma coisa ali o objetivo é esse, é estragar e não deixar funcionar, mas pelo menos naquela parte onde ele vai mexer, mas eu tenho medo, claro, mas mais medo dele assim, de como ele vai agir (...)" (P4).

Como consequências negativas ao realizar a cirurgia de vasectomia, baseando-se em estudos anteriores, os homens abordaram o medo do procedimento falhar e a companheira voltar a engravidar, ou ainda a possibilidade de arrependimento, numa situação em que o homem deseje ter mais filhos com uma nova companheira, ou aconteça morte dos filhos, ou ainda que a mulher insista muito em ter outro filho (Marchi et al., 2011).

"Certeza ninguém tem cem por cento de nada, tu tem que, a partir do momento que tu para e diz assim "faço ou não faço", o "ou não faço" tem algum porque. Claro que se pensa né, a vida é muito dinâmica, eu estou casado há dez anos e pretendo continuar casado até os últimos dias da minha vida, mas pode ser que amanhã a minha esposa olhe pra mim e diga "não, tu não é mais o homem da minha vida" ou vice-versa né, ai tu conhece uma outra pessoa, e sei lá, por cargas d'água, ela não tem filho, ai tu vê assim, pô mas en poderia proporcionar a maternidade, mas como eu perguntei para o doutor ontem, isso é reversivel? Não porque eu queira, mas pra ter isso como uma opção (...)” (P2).

Azevedo, Gonçalves e Rosa (2013), em estudo realizado com homens vasectomizados pelo SUS, observaram mudança na motivação masculina, visto que os homens sentiram a necessidade de dividir a responsabilidade do planejamento familiar com suas esposas ou companheiras. Ademais, os autores ressaltaram que os homens romperam com um grande tabu, uma vez que aceitaram a vasectomia como opção para o planejamento familiar, considerando que há alguns anos esta possibilidade gerava bastante resistência entre a população masculina.

\section{Considerações finais}

A presente pesquisa teve por objetivo apresentar uma análise do perfil de candidatos à esterilização masculina e suas expectativas diante da realização do procedimento, bem como suas representações sobre família e paternidade. Verificou-se que a maioria dos homens desejava ter filhos, ainda que as gestações tenham acontecido num momento não planejado pelo casal. Em alguns casos, o uso inadequado de métodos contraceptivos resultou em uma gravidez inesperada. No entanto, embora ocorrendo em um momento considerado como não ideal, os participantes reconheceram sua participação na gestação e assumiram as responsabilidades de pai.

Verificou-se uma concepção de paternidade em que o pai não se responsabiliza somente por prover o sustento dos filhos e impor limites, mas que se preocupa em suprir as necessidades dos filhos, como afeto, além de participar da sua educação, e de momentos de lazer com a família. Pode-se pensar que é justamente o fato de serem pais participativos e que entendem a importância de seu papel na vida dos filhos, que motivou a escolha destes homens pela realização do procedimento de vasectomia. Esta escolha parece representar as suas preocupações em serem pais presentes e dedicados, o que não seria viável caso tivessem mais algum filho.

A pesquisa demonstrou ainda que, entre as motivações dos participantes para a realização do procedimento de esterilização masculina, está a satisfação com a quantidade de filhos que possuem, estando de acordo, em sua maioria, com o planejamento familiar realizado pelo casal. Ademais, problemas relacionados ao uso de métodos contraceptivos, principalmente com o uso de anticoncepcional oral pelas mulheres, também motivaram a decisão dos participantes em realizar o procedimento, considerando seus efeitos colaterais a longo prazo para a saúde da mulher.

Referente às expectativas apresentadas, verificou-se que, após a realização do procedimento, os participantes esperam não se preocupar com problemas relacionados aos métodos contraceptivos, além de visar melhorias na relação do casal por não conceberem mais filhos que não estavam no seu planejamento e melhorias na qualidade de vida e saúde das mulheres.

Esta pesquisa visou contribuir com os estudos já realizados em planejamento familiar e de esterilização masculina, que ainda são relativamente escassos, além de buscar compreender os motivos que levam o homem a participar da concepção do casal e do planejamento familiar, para que se possa ter um maior engajamento 
destes nas políticas públicas para planejamento e saúde da família. Os resultados dessa pesquisa podem tornar-se úteis para analisar não somente o perfil descritivo dos pacientes que buscam o procedimento de esterilização masculina, mas também seu perfil qualitativo, considerando seus entendimentos de família e paternidade, de concepção e contracepção, planejamento familiar, sua subjetividade, receios e expectativas.

Tratando-se de um tema ainda pouco explorado, sugerem-se novas pesquisas, objetivando conhecer e entender melhor os pacientes que buscam o procedimento de esterilização masculina, visando ofertar esse serviço de acordo com a real necessidade desses pacientes e inseri-los cada vez mais nas políticas públicas voltadas para família e para o homem.

\section{Referências}

Azevedo, M. V. C., Gonçalves, M. C. \& Rosa, P. P. S. (2013). O homem vasectomizado pelo SUS. Interfaces Científicas - Saúde e Ambiente, 1(3), 35-46.

Badinter, E. (1993). XY: Sobre a identidade masculina (M. I. D. Estrada, trad.). Rio de Janeiro, RJ: Nova Fronteira.

Bardin, L. (2011). Análise de conteúdo. (L. A. Reto \& A. Pinheiro trad.). São Paulo, SP: Edições 70.

Bezerra, M. S., \& Rodrigues, D. P. (2010). Representações sociais de homens sobre o planejamento familiar. Revista da Rede de Enfermagem do Nordeste, 11(4), 127-134.

Biblioteca Virtual em Saúde do Ministério da Saúde. (2009). Dicas em saúde: Vasectomia. Retrieved in May 10, 2016, from http://bvsms.saude.gov.br/ bvs/dicas/197_vasectomia.html.

Botton, A., Cúnico, S. D., Barcinski, M. \& Strey, M. N. (2015). Os papéis parentais nas famílias: analisando aspectos transgeracionais e de gênero. Pensando Famílias, 19(2), 43-56.

Brasil, Ministério da Saúde. Secretaria de Políticas de Saúde. Área Técnica de Saúde da Mulher. (2002). Assistência em planejamento familiar: Manual técnico. (4th. ed.). Brasília, DF: Ministério da Saúde.

Camiá, G. E. K., Marin, H. F. \& Barbieri, M. (2001). Diagnósticos de enfermagem em mulheres que freqüentam serviço de planejamento familiar. Revista Latino-Americana de Enfermagem, 9(2), 26-34.

Cícero, A. C. V. F. P. P., Mandadori, F., Marcon, S. S. \& Barreto, M. S. (2014). Da decisão aos resultados: narrativa de homens adultos acerca da vasectomia. Revista de Pesquisa Cuidado é Fundamental Online, 6(4), 1372-1383, Retrieved in May 10, 2016, from http: http://www.seer.unirio.br/index. $\mathrm{php} /$ cuidadofundamental/article/viewFile/3354/pdf_654.

Cúnico, S. D. \& Arpini, D. M. (2013). O afastamento paterno após o fim do relacionamento amoroso: um estudo qualitativo. Interação em Psicologia, 17(1), 99-108.
Cúnico, S. D. \& Arpini, D. M. (2016). Significados de paternidade em famílias monoparentais femininas. Psicologia em Pesquisa, 10(2), 40-48.

Departamento de Saúde Reprodutiva e Pesquisa (SRP) da Organização Mundial da Saúde (OMS) e Escola Bloomberg de Saúde Pública/Centro de Programas de Comunicação (CPC) da Universidade Johns Hopkins, Projeto INFO. (2007). Planejamento Familiar: Um Manual Global para Prestadores de Serviços de Saúde. Baltimore e Genebra, Estados Unidos e Suíça: CPC e OMS.

Gaskell, G. (2002). Entrevistas individuais e grupais. In M. W. Bauer \& G. Gaskell (Eds.). (2002). Pesquisa qualitativa com texto, imagem e som: um manual prático (P. A. Guareschi, trad.). (2th. ed., pp. 64-89). Rio de Janeiro, RJ: Vozes.

Gomes, A. J. S. \& Resende, V. R. (2004). O pai presente: o desvelar da paternidade em uma família contemporânea. Psicologia: Teoria e Pesquisa, 20(2), 119-125.

Jager, M. E. \& Bottoli, C. (2011). Paternidade: vivência do primeiro filho e mudanças familiares. Psicologia: teoria e prática, 13(1), 141-153.

Lima, J. A., Serôdio, R. G. \& Cruz, O. (2011). Pais responsáveis, filhos satisfeitos: as responsabilidades paternas no quotidiano das crianças em idade escolar. Análise Psicológica, 29(4), 567-578.

Marchi, N. M., Alvarenga, A. T., Osis, M. J. D. \& Bahamondes, L. (2003). Opção pela vasectomia e relações de gênero. Caderno Saúde Pública, 19(4), 1017-1027.

Marchi, N. M., Alvarenga, A. T., Osis, M. J. D., Godoy, H. M. A., Guimarães, M. C. B. \& Bahamondes, L. (2011). Consequências da vasectomia: experiência de homens que se submeteram à cirurgia em Campinas (São Paulo), Brasil. Saúde e Sociedade, 20(3), 568-578.

Minayo, M. C. S. (2012). O desafio da pesquisa social. In M. C. S. Minayo (Ed.), \& S. F. D. R. Gomes, Pesquisa social: teoria, método e criatividade. (31 th. ed., pp. 9-29). Petrópolis, RJ: Vozes.

Moreira, K. A. P., Costa, A. A. R., Araújo, M. A. M. \& Queiroz, M. V. O. (2008). Causas e características da resistência à vasectomia em homens. Revista da Rede de Enfermagem do Nordeste, 9(2), 82-89.

Oliveira, A. G. \& Silva, R. R. (2011). Pai contemporâneo: diálogos entre pesquisadores brasileiros no período de 1998 a 2008. Psicologia Argumento, 29(66), 353-360.

Osis, M. J. D., Faúndes, A., Makuch, M. Y., Mello, M. B., Sousa, M. H., \& Araújo, M. J. O. (2006). Atenção ao planejamento familiar no Brasil hoje: reflexões sobre os resultados de uma pesquisa. Cadernos de Saúde Pública, 22(11), 2481-2490.

Ramires, V. R. R. (2014). A paternidade na contemporaneidade. In D. M. Arpini \& S. D. Cúnico (Orgs.). Novos olhares sobre a familia: aspectos psicológicos, sociais e jurídicos (pp. 27-38). Curitiba, PR: CRV.

Sutter, C. \& Bucher-Maluschke, J. S. N. F. (2008). Pais que cuidam dos filhos: a vivência masculina na paternidade participativa. PSICO, 39(1), 74-82.

Vieira, E. M., Fábio, S. V., Gueleri, W., Picado, M. P., Yoshinaga, E., \& Souza, L. (2005). Características dos candidatos à esterilização cirúrgica e os fatores associados ao tipo de procedimento. Cadernos de Saúde Pública, 21(6), 1785-1791.

Submetido em: 30-10-2017

Aceito em: 18-12-2018 